\title{
Article \\ Effect of Aluminum Ion Irradiation on Chemical and Phase Composition of Surface Layers of Rolled AISI 321 Stainless Steel
}

\author{
Pavel V. Bykov ${ }^{1}$, Vladimir Y. Bayankin ${ }^{1}$, Victor V. Tcherdyntsev ${ }^{2}{ }^{*} \mathbb{D}$, Vasiliy L. Vorob'ev ${ }^{1}$, Elena A. Pechina ${ }^{3}$, \\ Tatyana A. Sviridova ${ }^{2}$, Andrey A. Shushkov ${ }^{4}$, Andrey I. Chukavin ${ }^{1}$ and Svetlana S. Alexandrova ${ }^{5}$
}

\section{check for}

updates

Citation: Bykov, P.V.; Bayankin, V.Y.; Tcherdyntsev, V.V.; Vorob'ev, V.L.; Pechina, E.A.; Sviridova, T.A.; Shushkov, A.A.; Chukavin, A.I.; Alexandrova, S.S. Effect of Aluminum Ion Irradiation on Chemical and Phase Composition of Surface Layers of Rolled AISI 321 Stainless Steel. Metals 2021, 11, 1706. https:// doi.org/10.3390/met11111706

Academic Editor: Giovanni Principi

Received: 6 July 2021

Accepted: 13 October 2021

Published: 26 October 202

Publisher's Note: MDPI stays neutral with regard to jurisdictional claims in published maps and institutional affiliations.

Copyright: (C) 2021 by the authors. Licensee MDPI, Basel, Switzerland. This article is an open access article distributed under the terms and conditions of the Creative Commons Attribution (CC BY) license (https:// creativecommons.org/licenses/by/ $4.0 /)$.
1 Physical-Technical Institute, UdmFRC UB RAS, 426067 Izhevsk, Russia; bykovpv@udman.ru (P.V.B.); bayankinvya@udman.ru (V.Y.B.); vasily_1.84@udman.ru (V.L.V.); chukavin@udman.ru (A.I.C.)

2 Institute of New Materials and Nanotechnology, National University of Science and Technology "MISIS", 119049 Moscow, Russia; sviridova@misis.ru

3 Physical Technical Institute, Ural Branch, Russian Academy of Sciences, 426000 Izhevsk, Russia; el_pechina@mail.ru

4 Institute of Mechanics, UdmFRC UB RAS, 426067 Izhevsk, Russia; shushkov@udman.ru

5 Institute of Materials Science and Technology of Materials, Moscow Aviation Institute, 125993 Moscow, Russia; aleksandrovass@mai.ru

* Correspondence: vvch@misis.ru; Tel.: +7-9-104-002-369

Abstract: Commercial rolled AISI 321 stainless steel samples were irradiated with $\mathrm{Al}^{+}$ions with an energy of $80 \mathrm{keV}$ and fluence of $10^{17} \mathrm{ion} / \mathrm{cm}^{2}$. The effect of $\mathrm{Al}$ implantation on the chemical and phase composition of the steel surface layer was studied by X-ray electron spectroscopy and grazing beam mode of X-ray diffraction analysis. A thin surface layer down to a depth of $30 \mathrm{~nm} \mathrm{after} \mathrm{Al}^{+}$ions implantation consists mainly of metal oxides. In the near-surface layers of $5 \mathrm{~nm}$ in depth, a noticeable depletion in chromium and nickel was observed. A surface layer (up to $0.5 \mu \mathrm{m}$ ) of non-irradiated steel, in addition to the f.c.c. austenite $\gamma$-phase, consists of up to $20 \mathrm{vol} \%$ of the b.c.c. $\alpha^{\prime}$-phase, which formed at rolling as a result of mechanical deformation. Al implantation results in the significant increase in the $\alpha^{\prime}$-phase amount in the surface layer at a depth up to $2 \mu \mathrm{m}$. It is indicated that the observed $\gamma \rightarrow \alpha^{\prime}$ transformation at ion irradiation proceeds predominantly as a result of the effect of post-cascade shock waves, but not as a result of the surface layer chemical composition changes.

Keywords: stainless steel; aluminum; ion implantation; surface layer; phase composition

\section{Introduction}

Ion implantation causes changes in the physical, chemical, and mechanical properties of the surface layer of metals. By purposefully choosing the alloying element and ion irradiation modes, it is possible to provide a wide range of useful properties of the surface layers of materials, namely, to increase the strength and yield strength, impact strength, crack, corrosion, and wear resistance of metals and alloys [1-5].

In comparison with traditional methods of chemical and thermal treatment, ion implantation allows the ten-fold reduction of time and the steep decrease of the processing temperature, as well as the selective processing performance of parts of an article. A significant advantage of the method is the absence of a problem as related to adhesion between the modified layer and the bulk of material, which are typical for coating methods [6].

AISI 321 austenitic stainless steel (Fe/Cr18/Ni10/Ti) is widely used in construction, medicine, chemical, food, and oil refining industries for the manufacture of construction parts and various types of tanks and vessels. Moreover, specific applications of AISI 321 include the heat exchanger tube components for solar thermal generation [7] and pressurized water reactors in nuclear energy [8,9]. A combination of high mechanical properties with relatively low cost makes the AISI 321 steel attractive for industrial application. However, 
this steel possesses low corrosive resistance in aggressive oxidative media, as well as low wear resistance.

Various surface treatments, including ion implantation, were examined to improve the properties of AISI 321 steel. In [10], the effect of $\mathrm{Ar}^{+}$and $\mathrm{H}^{+}$ions irradiation on the electron work function was investigated. It was found that argon ions implantation results in a decrease in the electron work function, whereas irradiation by hydrogen ion results in an increase in this value. It was concluded that hydrogen ion implantation, in contrast to argon, can improve the corrosion resistance of AISI 321 steel. The effect of nitrogen ion irradiation on the surface properties of AISI 321 steel was studied in [11-13], in which a significant increase in surface hardness was observed as a result of nitrogen ion implantation. Moreover, a significant improvement of tribological characteristics as a result of nitrogen implantation was reported. In this case, no decrease in the corrosion resistance properties was observed [13]. Furthermore, an increase of AISI 321 steel wear resistance as a result of oxygen ion implantation was reported in [14].

The effect of metal ions implantation on the corrosion and thermal oxidation resistance behavior of AISI 321 steel was studied in detail by F. Noli and H. Baumann et al. in [15], the results of the $\mathrm{Zr}$ implantation on the thermal oxidation properties were reported. It was observed that $\mathrm{Zr}$ ions irradiation can improve the AISI 321 steel resistance to aqueous corrosion, whereas no positive effect of the treatment on the thermal oxidation resistance at elevated temperatures was found. In contrast to the above-mentioned case, the irradiation of AISI 321 by Y ions provides an increase of both thermal oxidation [16] and aqueous corrosion resistance [17]. The effect of $\mathrm{Mg}$ implantation on the thermal oxidation behavior $[18,19]$ shows that, at low temperatures, these samples exhibit a high oxidation resistance due to the inhibition of oxygen transport to the interface by $\mathrm{Mg}$ segregation at internal defects, whereas at higher temperatures, the oxidation properties were enhanced due to $\mathrm{Mg}$ diffusion from the interface into the bulk.

A comparison of the effects of $\mathrm{Mg-}, \mathrm{Y}-$, and Al-ions implantation on the corrosion behavior of AISI 321 steel was evaluated in [20]. It was observed that among the studied samples, the Al-implanted sample appears to be more resistant against corrosion due to strong adhesion, which increases with the formed surface modified layer. Thermal oxidation resistance of AISI 321 steel irradiated by $\mathrm{Al}$ ions with an energy of $40 \mathrm{keV}$ and doses of $10^{16}-3 \times 10^{17}$ ion $/ \mathrm{cm}^{2}$ was investigated in [21-23]. A significant increase in the oxidation resistance was observed for the Al-implanted samples, which was associated with the formation of protective layer containing both binary $\mathrm{Al}_{2} \mathrm{O}_{3}$ oxide and $\mathrm{Fe}$ or $\mathrm{Cr}$ containing spinels [22,23]. Diffusion of Al in Al-implanted AISI 321 steel was studied in [24]. It was observed that the diffusion rate is very low up to temperatures of $550{ }^{\circ} \mathrm{C}$. This diffusion behavior was found to be of benefit in the case of Al-implanted sample oxidation in $\mathrm{CO}_{2}$ atmosphere [22], since a low $\mathrm{Al}$ diffusivity provides an inhibition of the steel carburization. An increase in the implantation dose to $2 \times 10^{18}$ ion $/ \mathrm{cm}^{2}$ results in the formation of Al layer on the AISI 321 steel surface [25].

The investigations discussed above were carried out using the cast AISI 321 steel samples. However, some applications require steel supplied as a rolled sheet. It is known that AISI 321 is a metastable austenitic stainless steel. Martensite transformation in this steel can be induced both via thermal (using cooling to liquid nitrogen temperature) and mechanical mechanisms. It was reported [26] that martensite transformation in AISI 321 proceeds both at quasi-static and dynamic mechanical loading. Moreover, dry sliding results in austenite to martensite transformation in AISI 321 steel [27]. Due to the martensite phase transformation undesirable in terms of some applications, the elaboration of straininduced martensite content control methods is considered as an actual task [28]. As it was noted in [13], even a weak deformation at the pre-experimental sample polishing results in the formation of some amount of the $\alpha^{\prime}$-phase in the surface layer of AISI 321 steel. As the effect of ion implantation depends strongly both on the phase and chemical composition of irradiated materials $[12,13,29]$, it is of interest to investigate the peculiarities of ion implantation of an initially double-phase surface of rolled steel. Moreover, as it 
was reported in [26], a decrease of the grain size results in more intense strain-induced martensite transformation. It can be proposed that ion irradiation may be more effective in the case of an initially deformed surface with a fine grain structure.

\section{Materials and Methods}

AISI 321 rolled stainless steel was supplied by Chelyabinsk Metallurgical Plant, Chelyabinsk, Russia. The composition of steel AISI 321 in the initial state was: $\mathrm{Cr}-18 \mathrm{wt} \%$, $\mathrm{Ni}-10 \mathrm{wt} \%, \mathrm{Ti}-0.7 \mathrm{wt} \%$, and a small addition of $\mathrm{Mn}, \mathrm{Mo}$, and Si. The sheet was $2 \mathrm{~mm}$ thick. A precision cutting machine Polilab R30M, (LLC "Kemika”, Moscow, Russia) was used to obtain plates of $60 \mathrm{~mm} \times 9 \mathrm{~mm}$ in size. The samples were mechanically polished using polishing pastes GOI nos. 1 and 2 (JSC Reachim, Moscow, Russia) and cleaned in ethanol (LLC Kirovsky Biochemical Plant, Kirov, Russia).

Steel plates were irradiated using a setup of Institute of High Current Electronics, Russian Academy of Sciences, Siberian Branch, Tomsk, Russia, by $\mathrm{Al}^{+}$ions. Ion energy was $80 \mathrm{keV}$, dose was $10^{17}$ ions $/ \mathrm{cm}^{2}$, the current density in a pulse was $2.5 \mathrm{~mA} / \mathrm{cm}^{2}$, the pulse frequency was $5 \mathrm{~Hz}$, the pulse duration was $250 \mu \mathrm{s}$, the target temperature was no more than $50^{\circ} \mathrm{C}$, and the pressure in the chamber was no more than $5 \times 10^{-5}$ torr.

The microhardness of the surface layers of the samples before and after irradiation was measured by the Vickers method using a PMT-3M setup (JSC "Lomo", St. Petersburg, Russia), at a load of $0.196 \mathrm{~N}$ and held under a load for $10 \mathrm{~s}$. To increase the reliability of the result, the measurement procedure was performed ten times for one experimental point.

The nanoindentation tests were carried out using a complex system of measurements and research at the nanoscale NanoTest 600 (Micro Materials Ltd., Wrexham, UK), using a Berkovich indenter (a trihedral diamond pyramid with an apex angle of $65.3^{\circ}$ and a radius of curvature of about $200 \mathrm{~nm}$ ). The calculation of nanohardness was carried out in accordance with the method proposed by Oliver and Pharr [30]. The nanohardness was determined by analyzing the unloading curve and the indentation depth based on the loading-unloading diagram of the diamond indenter obtained during the tests. The initial data were chosen as follows: The maximum applied force was $1.5-60 \mathrm{mN}$, the maximum depth of penetration of the diamond indenter into the sample was within 40 to $700 \mathrm{~nm}$. The time of loading and unloading on the indentation point was $20 \mathrm{~s}$. A delay time at the maximum loading force was $10 \mathrm{~s}$, the distance between the indentation points was $25 \mu \mathrm{m}$. To increase the reliability of the result, the measurement procedure was performed twenty times for one experimental point.

The chemical composition of the surface layers was studied by the X-ray photoelectron spectroscopy (XPS) on a SPECS spectrometer (SPECS Surface Nano Analysis GmbH, Berlin, Germany) with a hemispherical energy analyzer (the energy resolution of $0.1 \mathrm{eV}$ ) with $\mathrm{Mg} \mathrm{K}_{\alpha}$ excitation of the photoelectron spectrum $(E=1253.6 \mathrm{eV})$. The energy scale of the spectrometer is calibrated according to the binding energies of the Au $4 \mathrm{f7} / 2(84 \mathrm{eV})$ and $\mathrm{Cu} 2 \mathrm{p} 3 / 2(932.8 \mathrm{eV})$ lines. The charge control of the samples was not used since they had sufficient conductivity. The full width at half maximum (FWHM) value for the Au 4f7/2 peak is $1 \mathrm{eV}$. The survey spectrum was recorded with a step of $1 \mathrm{eV}$ and the spectra of the internal levels of Fe 2p3/2, Al 2p, Al 2s, Ni 2p3/2, Cr 2p3/2, Ti 2p, O 1s, C 1s. The analysis of the spectra and revealing of the background part in them (according to the Shirley method) were carried out using the Casa XPS computer program. The atomic concentrations of elements were obtained from the spectra of internal levels by the method of relative coefficients of elemental sensitivity. The error in the magnitude of atomic concentrations is \pm 3 at $\%$. The distribution profiles of the elements were constructed using layer-by-layer etching of the surface with argon ions with an energy of $\sim 4 \mathrm{keV}$ at an etching rate of $\sim 1 \mathrm{~nm} / \mathrm{min}$. Under the conditions of ion etching, the structure of thin surface layers of the metal is disturbed. However, the positions of the spectral maxima remain unchanged. This makes it possible to judge the chemical state of the elements on a qualitative level after ion etching. 
The X-ray diffraction (XRD) patterns were recorded on an automated DRON 4.0 diffractometer (OJCS Burevestnik, St. Petersburg, Russia) using monochromatic $\operatorname{CoK}_{\alpha}$ and $\mathrm{CuK}_{\alpha}$ radiations. The pattern recording was realized in a grazing geometry (a sliding incident beam), which made it possible to obtain information from a layer which lies at a constant depth for all of the diffraction angles. The difference between symmetrical and asymmetric survey schemes is shown in Figure 1.

\section{The grazing beam \\ The focusing (Bragg-Brentano) geometry}
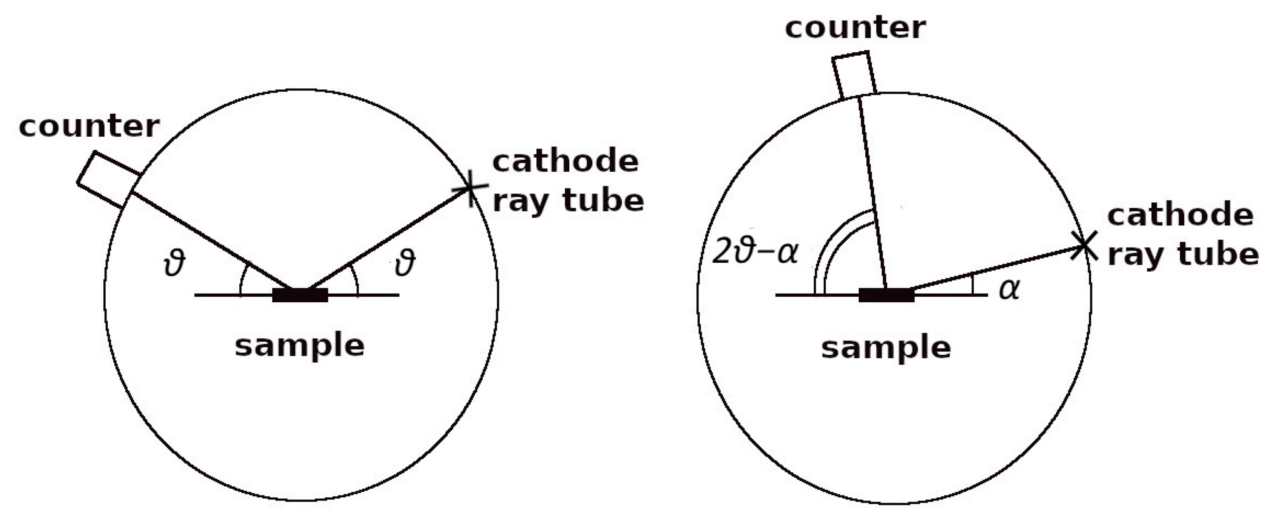

Figure 1. Symmetrical and asymmetrical diffraction geometries.

The depth from which information is obtained for the asymmetric scheme is proportional to $\sin \vartheta$. Therefore, at a constant angle of incidence, it is constant for all of the survey angles $2 \vartheta$. In the conventional symmetric scheme, the irradiated depth is proportional to $\sin \vartheta$, i.e., at larger diffraction angles, the information is obtained from deeper layers.

In the case that the materials have any structural peculiarities of sub-surface layers, in which depth is comparable to the penetration depth of X-ray radiation, the use of an asymmetric (grazing beam) scheme allows the realization of a correct phase analysis only from the sun-surface volume. Taking into account the known chemical composition of the steel under investigation, it is possible to estimate the penetration depth of X-rays (speaking more correctly, the thickness of the layer at which the rays are attenuated by a factor of the base of natural $\operatorname{logarithm} e$ ). They are shown in Table 1, where $\mu$ is a linear absorption coefficient.

Table 1. Penetration depth of X-rays.

\begin{tabular}{cccccc}
\hline \multirow{2}{*}{ Radiation } & $\boldsymbol{\mu}\left(\mathbf{c m}^{-\mathbf{1})}\right.$ & \multicolumn{4}{c}{$\begin{array}{c}\text { Thickness of the Layer at which the Rays Are Attenuated by } \\
\text { a Factor of } \boldsymbol{e} \text { Depending on the Beam Incidence Angle } \boldsymbol{\alpha}(\boldsymbol{\mu m})\end{array}$} \\
\cline { 2 - 5 } & & $\boldsymbol{\alpha}=\mathbf{2}^{\circ}$ & $\boldsymbol{\alpha}=\mathbf{5}^{\circ}$ & $\boldsymbol{\alpha}=\mathbf{1 0}^{\circ}$ & $\boldsymbol{\alpha}=\mathbf{1 5}^{\circ}$ \\
\hline $\mathrm{CuK}_{\alpha}$ & 2242 & 0.15 & 0.34 & 0.59 & 0.76 \\
$\mathrm{CoK}_{\alpha}$ & 950 & 0.35 & 0.82 & 1.45 & 1.90 \\
\hline
\end{tabular}

The quantitative analysis of the phase composition of multiphase sample can be carried out by taking into account the known relation for the integrated intensity of the phase line:

$$
I_{\alpha}^{\text {exp }}=I_{0} \cdot C \cdot I_{\alpha}^{\text {theor }} \cdot A(\theta) \cdot v_{\alpha}
$$

where $A(\theta)=1 / 2 \bar{\mu}$ and $\bar{\mu}$ are linear absorption coefficients, $I_{0}$ is the number of quanta emitted by the X-ray tube per unit of time. It should be noted that the coefficient of linear attenuation of a phase depends on its elemental composition and on the radiation wavelength, and depending on the latter, the so-called absorption jumps occur. A classic example is iron, for which this jump lies exactly between the $\mathrm{CoK}_{\alpha}$ and $\mathrm{CuK}_{\alpha}$ wavelengths, which leads to a sharp change in the penetration depth when changing radiation. It allows 
the application of these combinations of radiations for phase analysis of the Fe-based material surface.

The spectrum of a multiphase sample is a linear combination of the spectra of the individual phases. The spectrum coefficients are a function of (a) volume fractions of phases $v_{\alpha}$; (b) the coefficient of linear attenuation of the sample; (c) the magnitude of the absolute intensity, which depends on the scattering ability of the atoms that make up the unit cell of the phase, as well as on the repeatability factor on the symmetry of the crystal lattice. The volume fraction of the phases $v_{\alpha}$ can be found by calculating or measuring the linear attenuation coefficients of the phases and the sample and by obtaining the absolute intensity $I_{\alpha}^{\text {theor }}$ of the phases. There are several ways to accomplish this. In our case, the quantitative phase analysis was performed by the Rietveld method according to the published procedure [31] using the PHAN\% software (Version 2.0, NUST MISIS, Moscow, Russia).

The method is based on the calculation of the absolute intensities $I_{H K L}^{\text {theor }}$ in the kinematic approximation from the data on the crystal structure. If the structure is known and determined correctly, this is the best way to conduct the quantitative phase analysis. It allows the calculation of the intensities of all phase lines for the used survey geometry in the same units and does not require pure phases investigation. The experimentally measured (HKL) line intensity of the pure phase $I_{H K L}^{\exp }$ is proportional to its theoretical absolute intensity $I_{H K L}^{\text {theor }}$ divided by the linear X-ray absorption coefficient for phase $\mu$, i.e.,

$$
I_{H K L}^{\text {exp }} \sim I_{H K L}^{\text {theor }} \cdot v_{\alpha} / \mu
$$

In a multiphase sample, rather than the phase attenuation coefficient, it is necessary to use the average sample attenuation coefficient $\bar{\mu}$. In turn,

$$
I_{H K L}^{\text {theor }}=P_{H K L} \cdot\left|\frac{F_{\mathrm{HKL}}^{\text {cell }}}{V_{\text {cell }}}\right|^{2} \cdot e^{-2 M} \cdot K(\vartheta),
$$

where $P_{H K L}$ is the repeatability factor, $F_{\mathrm{HKL}}^{\text {cell }}$ is the structural amplitude of the cell taking into account atomic factors and dispersion corrections, $V_{\text {cell }}$ is the unit cell volume of the phase, $e^{-2 M}$ is the temperature factor, and $K(\vartheta)$ is the angular factor.

When fitting the spectrum, the function is minimized, which is the sum of the squares of the differences between the experimental and model spectra at each point of the survey. The model spectrum is the sum of the background and the model spectra of individual phases. The contribution from each phase $\alpha$ is proportional to its volume fraction $v_{\alpha}$. When calculating the model spectrum from each phase, the contribution of block and deformation broadening is taken into account. It is possible to take into account the geometric broadening and line shift associated with absorption and alignment errors. The shape of the lines is approximated by a Lorentzian of the corresponding multiplicity or a more complex Voigt function. The background is polynomial and the coefficients of polynomials of different degrees are determined in the course of solving the problem of minimizing the function.

Systematic errors when using the described method of phase analysis can arise for various reasons. In our case, one source of errors can be the presence of texture in the samples. However, the used software allows us to take the texture effect into account. A more serious source of errors can be associated with the depth dependence of the chemical compositions of the phases. The absolute intensity strongly depends on the scattering ability of the atoms. As a result, in the case of the formation of solid solutions, to reduce the error in the volume fractions, the true elemental composition of the phases should be taken into account in the calculation. It is true that if the solution is formed by neighboring elements in the periodic table, this factor is negligible. However, in our case, in the irradiated sample, the implantation of aluminum was carried out, and the aluminum atomic number is twice lower than the atomic number of iron. Judging by the 
lattice periods, the b.c.c. phase has a slightly increased lattice period, thus the aluminum could probably dissolve in it. Upon dissolution of up to 10 at $\%$ aluminum in iron, the volume fractions can be overestimated by $2-3 \mathrm{vol} \%$ towards an increase in the content of the $\alpha^{\prime}$-phase in relation to the true value.

The metallographic studies were performed using a Neophot-21 optic microscope (Carl Zeiss, Jena, Germany). Grinding and polishing of the cross-section of the cut part was carried out mechanically. After polishing, the objects were etched with two different reagents: (1) nitric acid $(20 \mathrm{~mL})$, perchloric acid $(60 \mathrm{~mL})$, and ferric chloride $(20 \mathrm{~g})$; (2) oxalic acid and water (electrolytic etching under a voltage of 1-6 V). All of the reagents were purchased from JSC Reachim, Moscow, Russia.

The microstructure studies were performed using a Thermo Fisher Scientific Quattro $\mathrm{S}$ scanning electron microscope (Thermo Fisher Scientific, Prague, Czech Republic). The measurements were carried out at an accelerating voltage of $5 \mathrm{kV}$ and a beam current of $0.29 \mathrm{pA}$. A cross-section for grain structure studying was made using a SEMPrep2 SC-2000 setup (Technoorg Linda, Budapest, Hungary) by etching the surface with $\mathrm{Ar}^{+}$ions with an energy of $10 \mathrm{keV}$ and with the possibility of cooling the sample with a Peltier element. The heating temperature of the samples during the operation did not exceed $60{ }^{\circ} \mathrm{C}$.

\section{Results and Discussion}

Figure 2 shows the dependence of nanohardness on the penetration depth of indenter. The depth of nanohardness in the initial state is approximately constant and lies in the range 3.3-3.5 GPa, and reaches 3.8-4 GPa only in a thin surface layer $(<100 \mathrm{~nm})$. After irradiation with aluminum ions, the nanohardness in a thin surface layer $(<100 \mathrm{~nm})$ significantly increases (5.4 GPa at a depth of $75 \mathrm{~nm}$ and $6.1 \mathrm{GPa}$ at a depth of $60 \mathrm{~nm}$ ) and reaches $12.7 \mathrm{GPa}$ at a depth of $40 \mathrm{~nm}$. With the increasing depth, the nanohardness decreases, but still remains much higher than in the initial state (4.8-4.9 GPa vs. 3.3-3.5 GPa at a depth of $450-670 \mathrm{~nm}$ ).

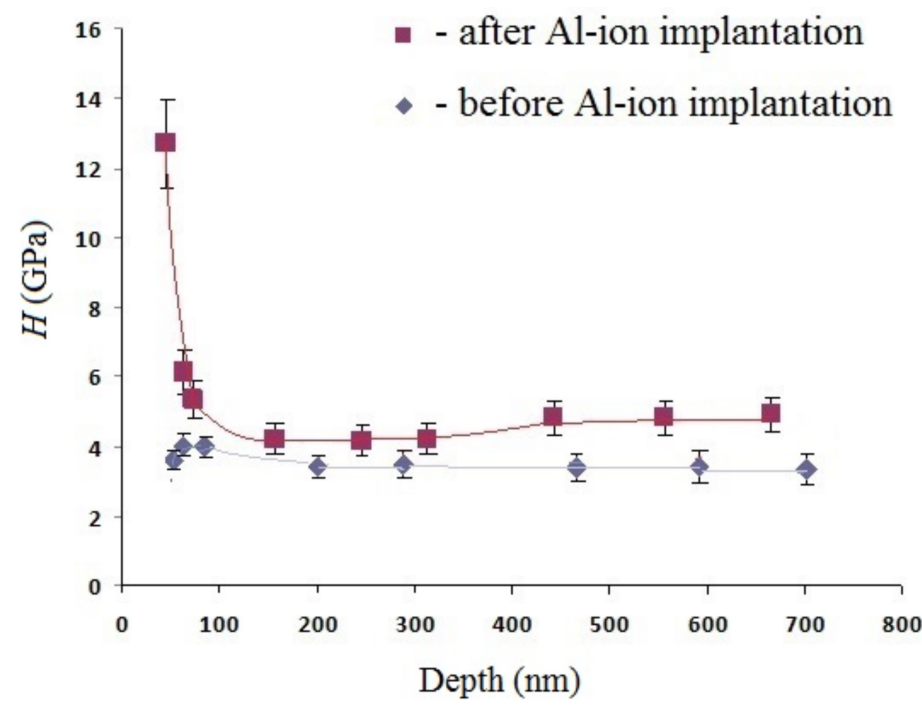

Figure 2. Dependence of nanohardness on the penetration depth of indenter before and after irradiation with aluminum ions.

The microhardness was measured before and after irradiation of the plates. The measurements showed that the hardness of the plates increased from 1.5 to $2.5 \mathrm{GPa}$ as a result of Al-ions implantation. The penetration depth of indenter was 2.2 and $1.7 \mu \mathrm{m}$, respectively. An increase in the microhardness by 1.5 times and more is a typical result of ion implantation [11-13] and can be the evidence of significant changes in the surface layer of steel as a result of irradiation. 
The XPS method was used to study the chemical composition of surface layers before and after irradiation with aluminum ions. Figure 3 shows the elemental depth profiles of the samples before and after $\mathrm{Al}$ implantation. As it was noted above, $1 \mathrm{~min}$ of tentative corresponds to $1 \mathrm{~nm}$ of depth. In the non-irradiated state, the elemental composition (Figure 3a) changes to a depth of $5 \mathrm{~nm}$, and then the chemical composition corresponds to the sample bulk. Al implantation significantly changes the composition of the surface layer of steel. Figure $3 b$ shows that the depth profile of implanted aluminum is a curve with a broad peak, which is typical for implanted elements [21-23]. The maximum aluminum concentration of $27 \mathrm{at} \%$ was reached at a depth of $20 \mathrm{~nm}$. The calculation by the SRIM method [32] showed that the projected range of aluminum ions with an energy of $80 \mathrm{keV}$ in AISI 321 stainless steel is $R_{\mathrm{p}} \approx 54.4 \mathrm{~nm}$, and the longitudinal straggling is $\Delta R_{\mathrm{p}} \approx 31 \mathrm{~nm}$. In a thin surface layer (up to $5 \mathrm{~nm}$ ), the contents of chromium and nickel sharply decrease relative to the initial values. Depletion in $\mathrm{Cr}$ and $\mathrm{Ni}$ in the near-surface area was previously observed in Y- and Zr-implanted AISI 321 steel [15-17]. At a depth of 10 and $20 \mathrm{~nm}$, the content of chromium increases sharply. Starting from a depth of $30 \mathrm{~nm}$, the chromium concentration falls below the initial values, whereas the nickel content gradually increases and achieves the value corresponding to that for the sample bulk.

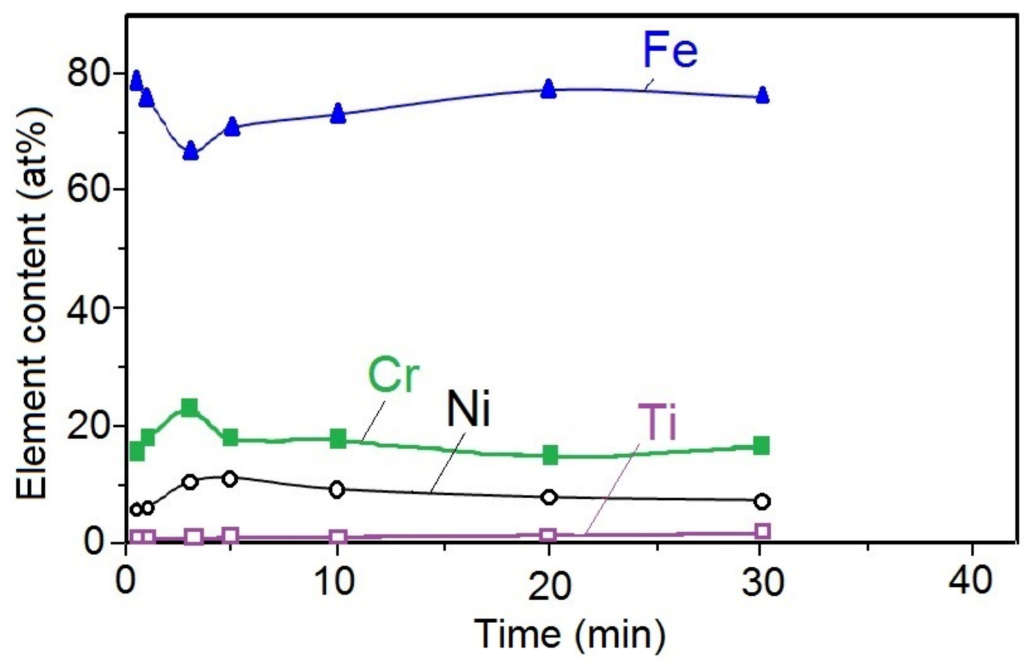

(a)

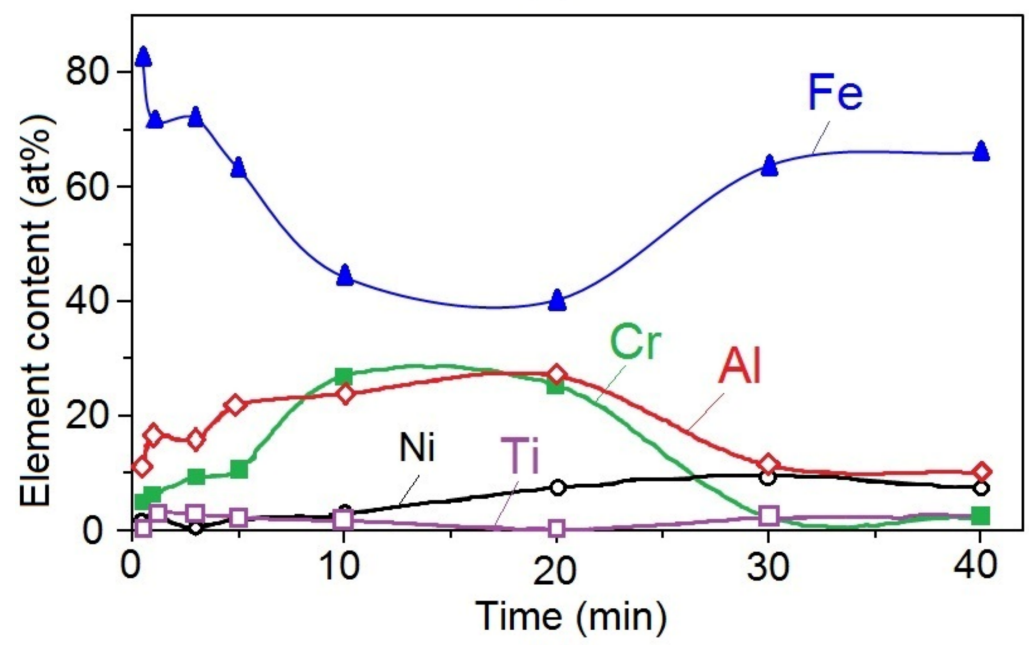

(b)

Figure 3. Depth distributions (XPS data) of the elemental composition of sample surface before (a) and after (b) Al-ion implantation obtained using layer-by-layer etching of surface with argon ions with an energy of $\sim 4 \mathrm{keV}$ at an etching rate of $\sim 1 \mathrm{~nm} / \mathrm{min}$, i.e., here $1 \mathrm{~min}$ of tentative corresponds to $1 \mathrm{~nm}$ of depth. 
According to the XPS data, aluminum at different depths is in different compounds (Figure $4 \mathrm{a}$ ). The predominant state of aluminum with the position of the spectrum maximum at $E_{\mathrm{b}}=74.8 \mathrm{eV}$ is manifested practically throughout the entire depth of the analyzed layer in the Al2p spectrum. This state corresponds to the bond of aluminum with oxygen Al-O bond [33-35]. For example, the formation of aluminum oxide $\mathrm{Al}_{2} \mathrm{O}_{3}$ [34] or alumina of substoichiometric composition $\mathrm{AlO}_{\mathrm{x}}$ [33] is possible. In particular, the oxides of substoichiometric composition $\mathrm{AlO}_{\mathrm{x}}$ are found in a natural oxide film on the surface of pure aluminum [33]. As the depth of the analyzed layer increases, a shoulder with $E_{\mathrm{b}}=72.8 \mathrm{eV}$ appears in the Al2p spectrum from the side of lower energies (Figure 4a). This indicates that, at these depths, the state of aluminum with a metallic type of interatomic bonds is manifested [33]. The analysis of the Ni2p3/2 spectra showed that nickel atoms at a depth of about $10 \mathrm{~nm}$ are in a state corresponding to the bonds of nickel with oxygen Ni-O (Figure $4 \mathrm{~b}$ ). This is evidenced by the peak with $E_{\mathrm{b}}=853.6 \mathrm{eV}$ and its respective satellites at higher binding energy [36,37]. However, with increasing depth (for example, at depths of 20 and $30 \mathrm{~nm}$ ), the Ni2p3/2 spectrum is completely transformed and consists of the main peak and the associated satellite peak located 6-8 eV higher than the binding energy of the main peak (Figure $4 \mathrm{~b}$ ). At a depth of $30 \mathrm{~nm}$, the main peak of the Ni2p3/2 spectrum falls on the binding energy of $853.2 \mathrm{eV}$, and the satellite peak, which is relatively low-intensity and wide, is at a distance of about $6 \mathrm{eV}$ from the main peak. These energies indicate that nickel atoms at this depth are in the metallic state [38].

(a)

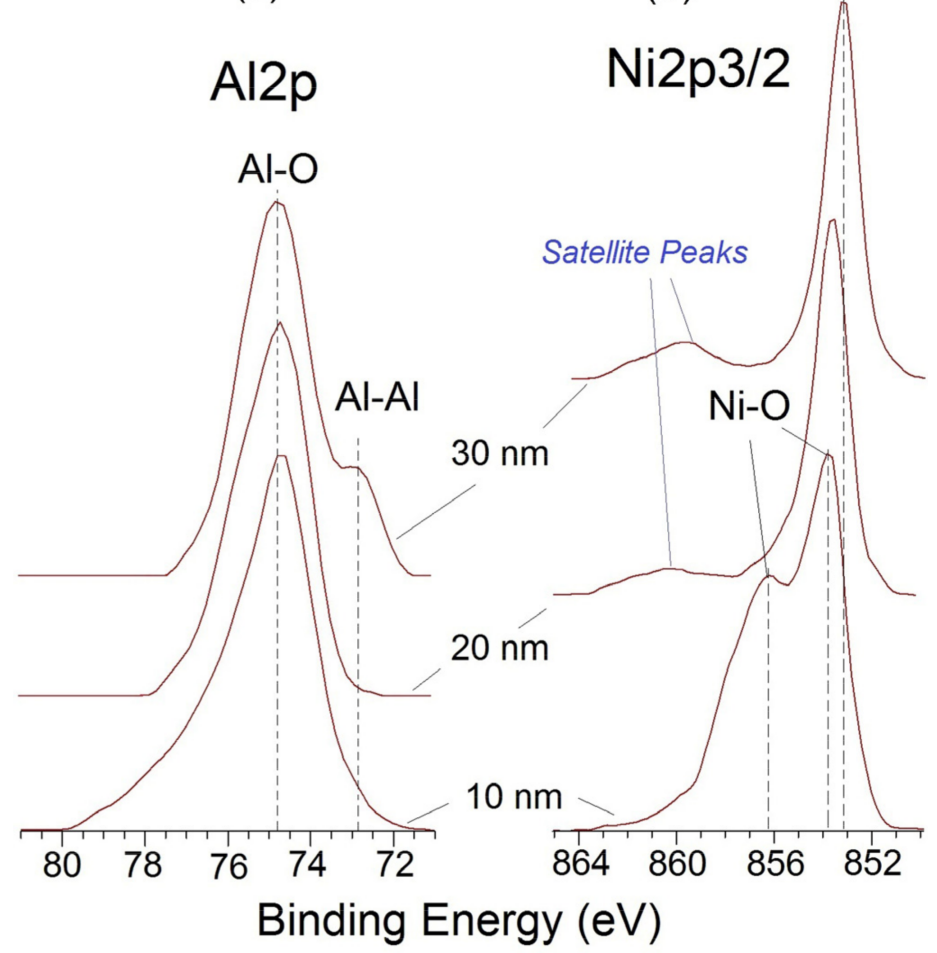

Figure 4. Al2p (a) and Ni2p3/2 (b) XPS spectra on various depths (indicated near curves) of the $\mathrm{Al}^{+}$ ions irradiated sample.

The Fe2p3/2 and Cr2p3/2 spectra can be used to analyze the state of iron and chromium atoms in the modified layer. The spectra show that both iron and chromium atoms are in the oxidized state to a depth of $\sim 10 \mathrm{~nm}$ (Figure $5 \mathrm{a}, \mathrm{b}$ ) with binding energies of 709.8 and $577.2 \mathrm{eV}$, respectively [33]. Probably, iron and chromium oxides with various oxidation states $(+2,+3$, etc.) form. At a depth of $\sim 20 \mathrm{~nm}$, chromium atoms continue to be predominantly in the oxidized state $\left(E_{\mathrm{b}}=577.2 \mathrm{eV}\right)$, and iron atoms, both in the oxidized state $\left(E_{\mathrm{b}}=577.2 \mathrm{eV}\right)$ and in the metallic state $\left(E_{\mathrm{b}}=707 \mathrm{eV}\right)$. As the depth increases (at a depth of $\sim 30 \mathrm{~nm}$ ), iron atoms are mainly in the metallic state (Figure $5 \mathrm{a}$ ), while chromium 
atoms are in both the metallic and oxidized states (Figure $5 b$ ). The metallic state of atoms of iron, nickel, and chromium is understood as the state of these atoms in the nodes of the crystal lattice of the solid solution. Therefore, the analysis of the XPS spectra of aluminum and the main components of the alloy suggests that a thin nanoscale surface layer (more than $30 \mathrm{~nm}$ deep) after implantation of $\mathrm{Al}^{+}$ions consists mainly of metal oxides. However, if the presence of nickel and iron oxides is limited to a depth of $\sim 30 \mathrm{~nm}$, chromium oxides extend to great depths. It is assumed that this is due to the higher chemical affinity of chromium atoms to oxygen and, most likely, causes the enrichment of a thin surface layer $\sim 30 \mathrm{~nm}$ in depth with chromium atoms and depletion of this layer in nickel and iron atoms [39].

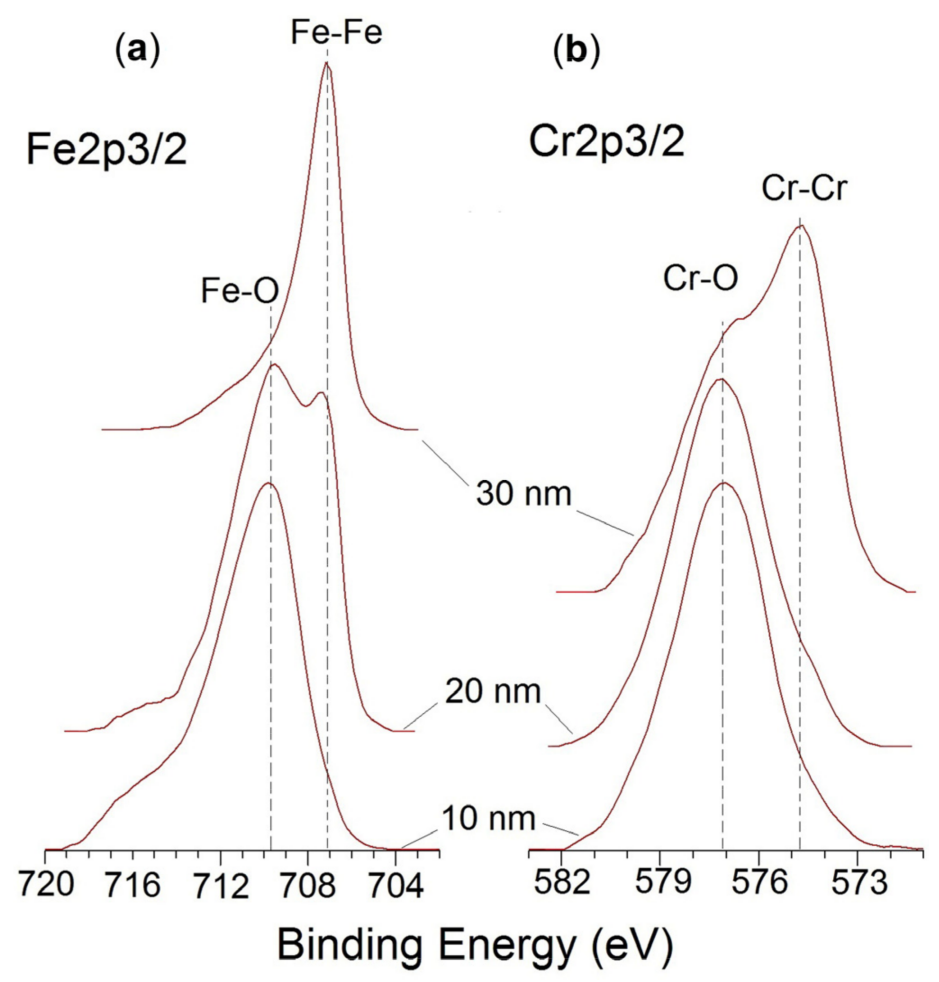

Figure 5. Fe2p3/2 (a) and Cr2p3/2 (b) XPS spectra on various depths (indicated near curves) of the $\mathrm{Al}^{+}$ions irradiated sample.

Figures 6 and 7 show the XRD patterns on the non-irradiated and irradiated samples, respectively. As it can be seen from Figure 6, the diffraction patterns obtained using $\mathrm{CuK}_{\alpha}$ radiation, which show the structure of near-surface zone, contain visible peaks as related to the $\alpha^{\prime}$-phase, whereas the diffraction patterns obtained using $\mathrm{CoK}_{\alpha}$ show nearly singlephase austenitic structure. It reveals that the $\gamma \rightarrow \alpha^{\prime}$ transformation after rolling of steel proceeds in the surface layer only. Figure 7 shows that after the $\mathrm{Al}$ implantation, the intensity of XRD peaks as related to the $\alpha^{\prime}$-phase increased strongly. The realization of $\gamma \rightarrow \alpha^{\prime}$ transformation in steels as a result of ion implantation was reported previously $[40,41]$. It should be noted that in [13], no ion irradiation induced phase transformation was observed in austenitic AISI 321 steel, whereas duplex austenitic-ferritic AISI 318 steel shows the $\gamma \rightarrow \alpha^{\prime}$ transformation at the same irradiation condition. As it was reported in [42], ion irradiation of AISI 316L single-phase austenitic stainless steel obtained by selective laser melting results in the formation of no new phases, whereas the intensive $\gamma \rightarrow \alpha^{\prime}$ transformation at ion irradiation was observed for the same steel after cold rolling. Therefore, we can propose that the presence of $\alpha^{\prime}$ phase in the initial structure can promote the intensive $\gamma \rightarrow \alpha^{\prime}$ transformation at ion irradiation. 


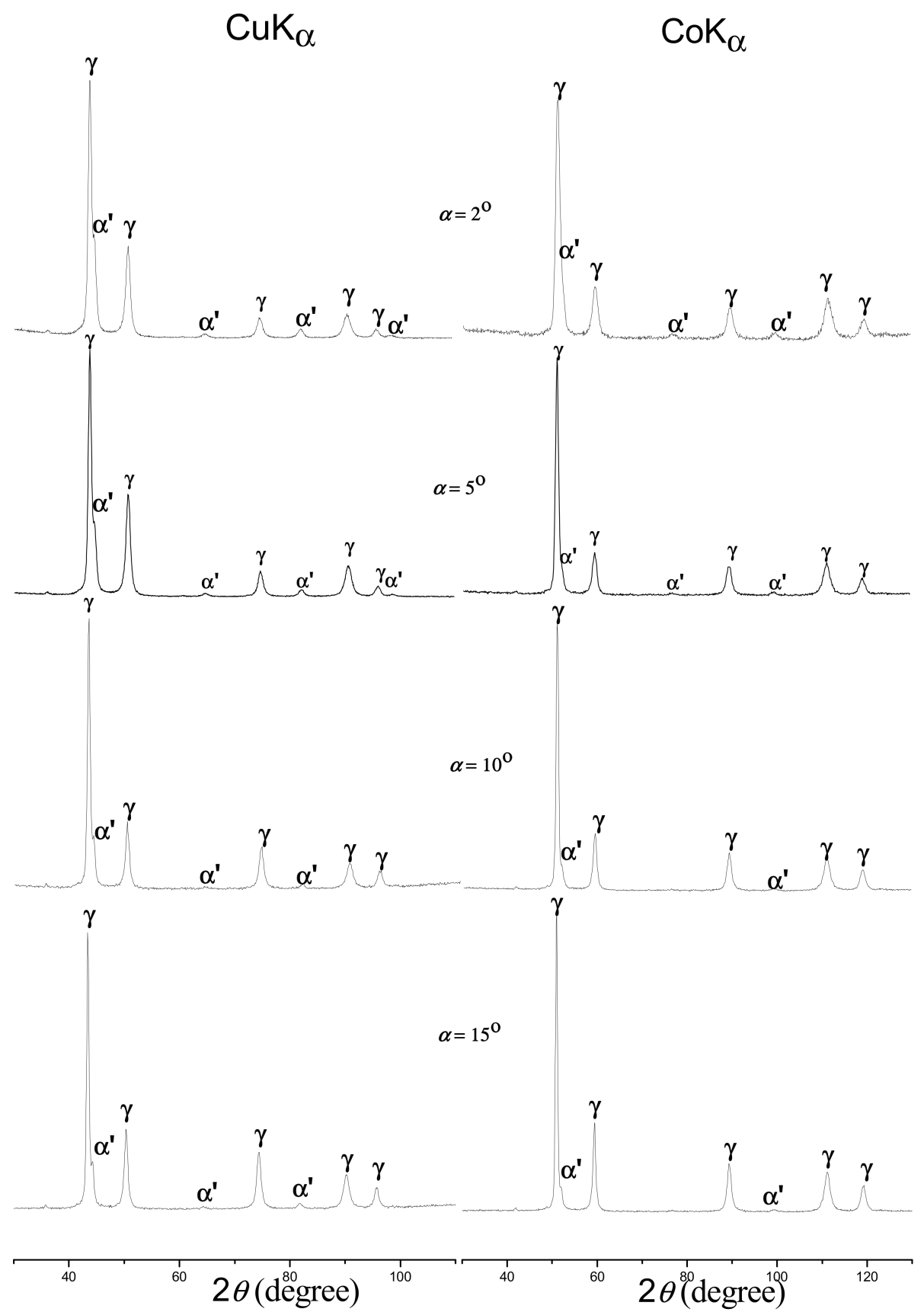

Figure 6. XRD patterns of initial AISI 321 steel obtained using $\mathrm{CuK}_{\alpha}$ and $\mathrm{CoK}_{\alpha}$ at various beam incident angles $\alpha$.

Figure 8 shows the depth dependences of the phase composition for as-received and Al-implanted steel. As it follows from the curves, before and after implantation, the b.c.c. phase is located in the near-surface layers, in which the amount of this phase decreases with an increase in the thickness of the analyzed layer. However, for the irradiated sample, the fraction of the $\alpha^{\prime}$ phase is noticeably higher than for the as-received steel. 


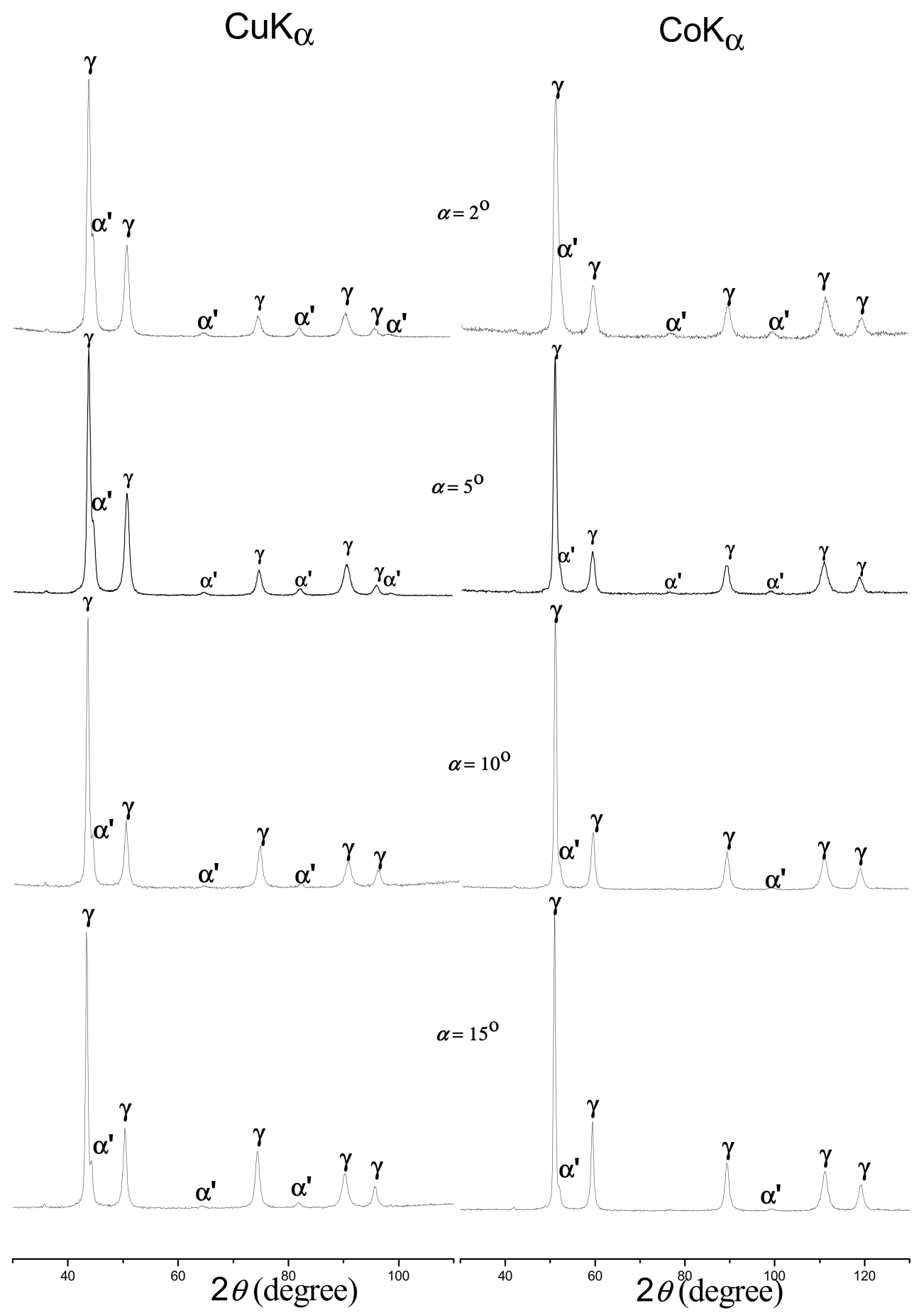

Figure 7. XRD patterns of Al-implanted AISI 321 steel obtained using $\mathrm{CuK}_{\alpha}$ and $\mathrm{CoK}_{\alpha}$ at various beam incident angles $\alpha$.

The dependences on Figure 8 were plotted using the data obtained by both $\mathrm{CuK}_{\alpha}$ and $\mathrm{CoK}_{\alpha}$ radiations: To analyze the upper surface layers, $\mathrm{CuK}_{\alpha}$ was used, and for deeper layers, $\mathrm{CoK}_{\alpha}$ was used. The unirradiated steel surface is characterized by the presence of $\gamma+\alpha^{\prime}$ phase mixture. The volume fraction of the $\alpha^{\prime}$-phase decreases from $25 \%$ to $3 \%$ when the depth increases from $100 \mathrm{~nm}$ to $1.4 \mu \mathrm{m}$. It is known that the plastic deformation of these steels contributes to the $\gamma \rightarrow \alpha^{\prime}$ transformation. A large amount of the $\alpha^{\prime}$-phase in the near-surface sections of the strip was obtained by rolling. In addition, its practical absence at depths greater than $1.5 \mu \mathrm{m}$ from the strip surface are apparently due to the 
inhomogeneous deformation arising during rolling, due to the fact that when the belt passes between the rollers, the middle volumes are deformed less.

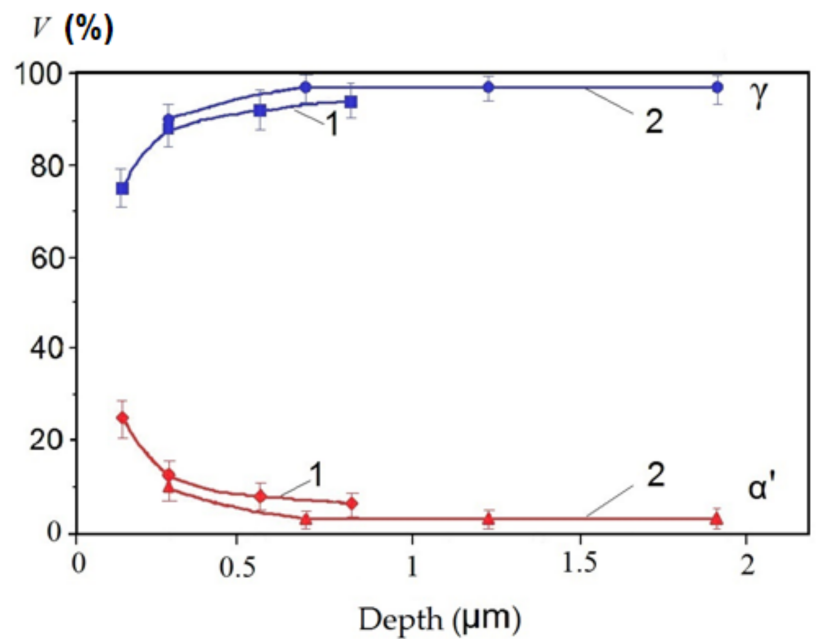

(a)

\section{$V(\%)$}

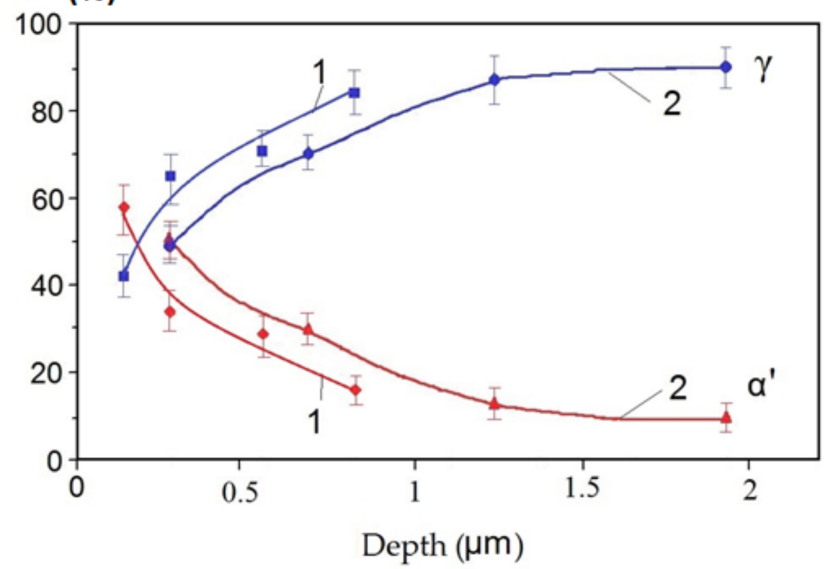

(b)

Figure 8. Depth dependences of phase composition for as-received (a) and Al-irradiated (b) steel, obtained from XRD data collected using $\mathrm{CuK}_{\alpha}(1)$ and $\mathrm{CoK}_{\alpha}(2)$ radiations. $V$ is the phase volume fraction, $\%$.

The XRD data for the steel surface after irradiation show that at a depth of $150 \mathrm{~nm}$ the volume fraction of the $\alpha^{\prime}$-phase is about $60 \%$. An increase in the distance from the sample surface results in a decrease in the $\alpha^{\prime}$-phase content. The increased content of the $\alpha^{\prime}$-phase in the irradiated samples in comparison with the unirradiated samples is the evidence for the $\gamma \rightarrow \alpha^{\prime}$ transformation under the action of bombardment with aluminum ions.

Figure 9 shows the micrographs of the cross-sections of the plates before and after irradiation with aluminum ions. The first reagent was used to etch the initial sample and the sample after irradiation (Figure $9 a, c)$, and the second, for the sample after irradiation (Figure $9 \mathrm{~b}$ ). It can be seen from the micrographs that after etching with the first reagent, a modified layer (Figure 9c) with a thickness of $\approx 1 \mu \mathrm{m}$ is found, which is etched at a higher rate than the bulk of the sample. With further etching, the surface layer is over-etched and disappears. When etching with a solution of oxalic acid (Figure 9b), a changed layer is revealed, which is oxidized at etching. The thickness of this layer is up to $40 \mu \mathrm{m}$. 


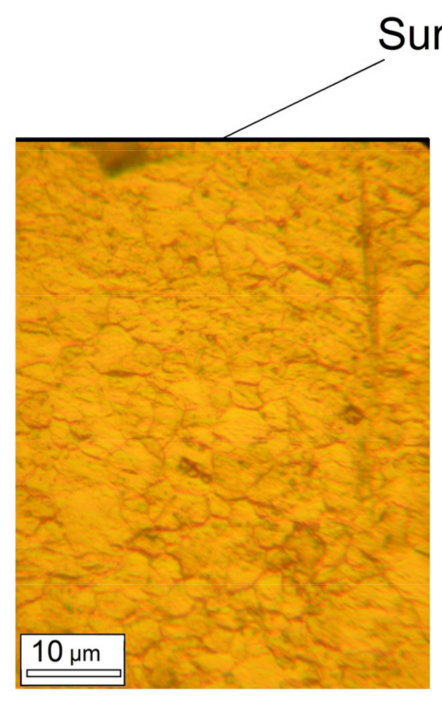

(a)

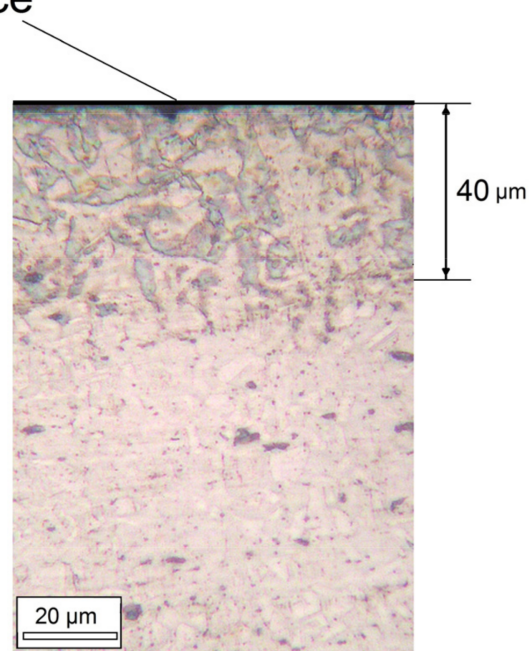

(b)

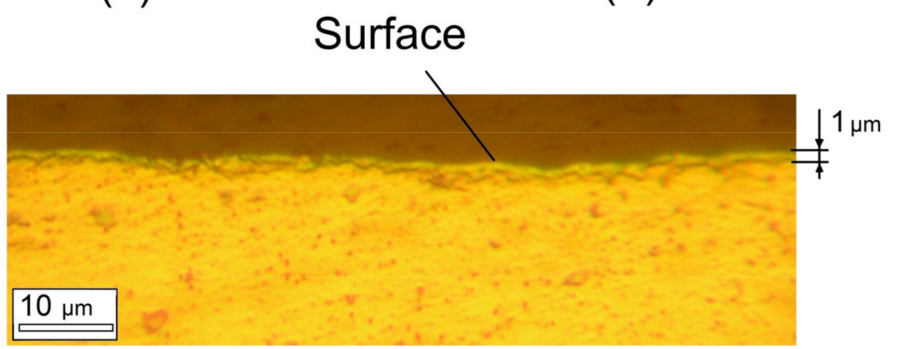

(c)

Figure 9. Optical micrographs of initial (a) and Al-implanted samples etched with reagent $1(\mathbf{a}, \mathbf{c})$ and reagent 2 (b).

The SEM study of cross sections of the samples before and after irradiation did not reveal a difference in the microstructure of the samples in the near-surface layers up to $\sim 3 \mu \mathrm{m}$ deep (Figure 10a,b, scale of $10 \mu \mathrm{m}$ ). This is due to the fact that during ion etching, the channels appear in these layers, which are inherited from the microrelief (roughness) of the surface and distort the appearance of the microstructure. The microstructure of the surface layers (up to $\sim 100 \mu \mathrm{m}$, the incision depth) of the initial and irradiated samples can be represented as consisting of two zones (Figure 10a,b, scale of $50 \mu \mathrm{m}$ ). Zone 1 is characterized with relatively equiaxed grains approximately $40 \mu \mathrm{m}$ in size for the initial sample (Figure 10a). In zone 2, the grain structure is in a distorted, deformed state due to the rolling of the samples. Comparing the microstructures of the initial and irradiated samples, it can be seen that in the sample after irradiation, the boundary between zones 1 and 2 looks slightly more diffuse and the grains in zone 1, at first glance, have smaller sizes, which is more clearly manifested in the images with smaller scales of 20 and $10 \mu \mathrm{m}$ (Figure 10b).

As it is follows from Figures 8 and 9c, the ion irradiation affects the phase composition and structure of the investigated steel at a depth of up to $1 \mu \mathrm{m}$, whereas the possible penetration depth of aluminum ions in steel does not exceed $85 \mathrm{~nm}$ [32]. It may be an evidence for long-range effect of ion irradiation, which was described, for instance, in [43].

The changes in the structure and properties of materials due to the generation and movement of dislocations in the fields of static stresses created by implanted impurities, as well as a result of ion irradiation-initiated structural-phase transformations of a radiationdynamic nature (post-cascade shock waves), can also be observed much deeper, up to $10^{4}-10^{5} R_{\mathrm{p}}$ [44,45]. This leads to the formation of a modified layer with a thickness of $\approx 1 \mu \mathrm{m}$ (Figure 9c), which in turn leads to an increase in the microhardness. Moreover, as it was reported in [44], the long-range effect of ion irradiation was observed for severe deformed foils only, whereas for annealed foils no long-range effect of ion irradiation was 
found. Our results can be considered as additional evidence for the dependence between structure deformation and long-range effect of ion irradiation.
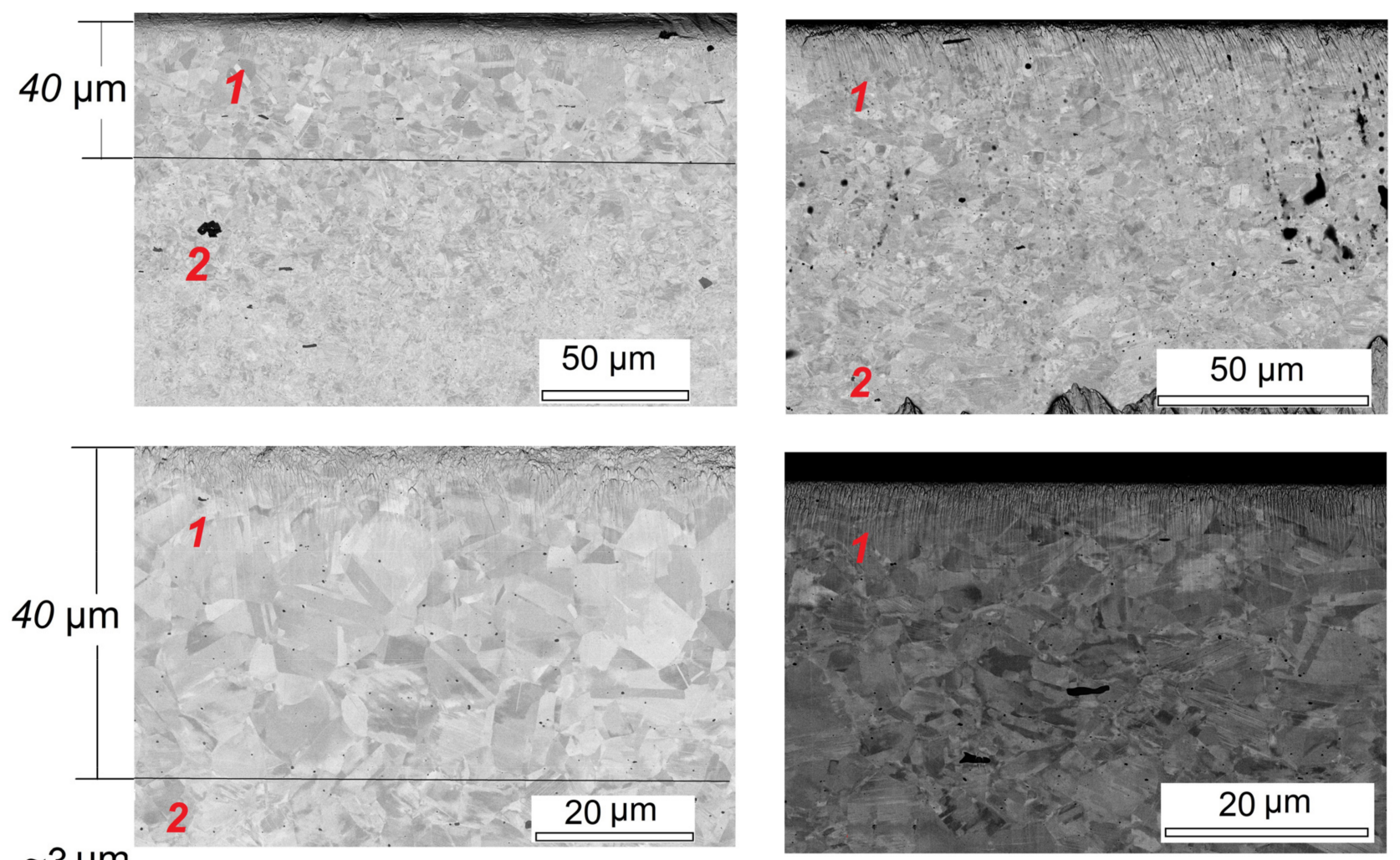

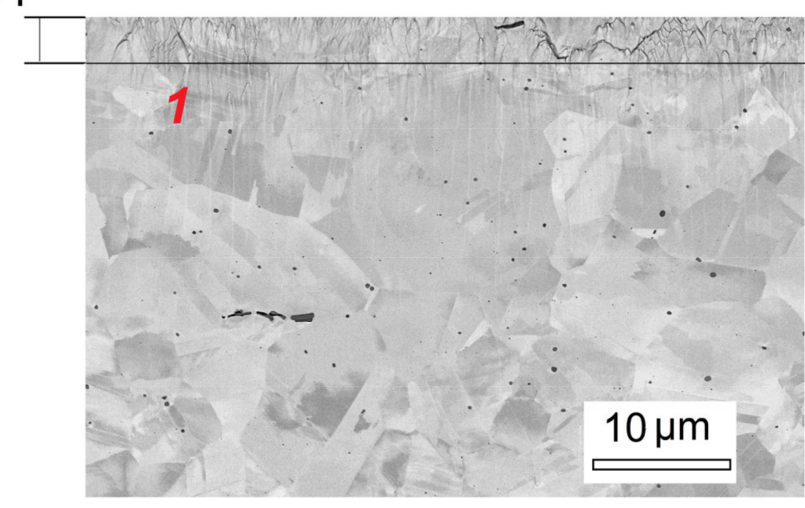

(a)

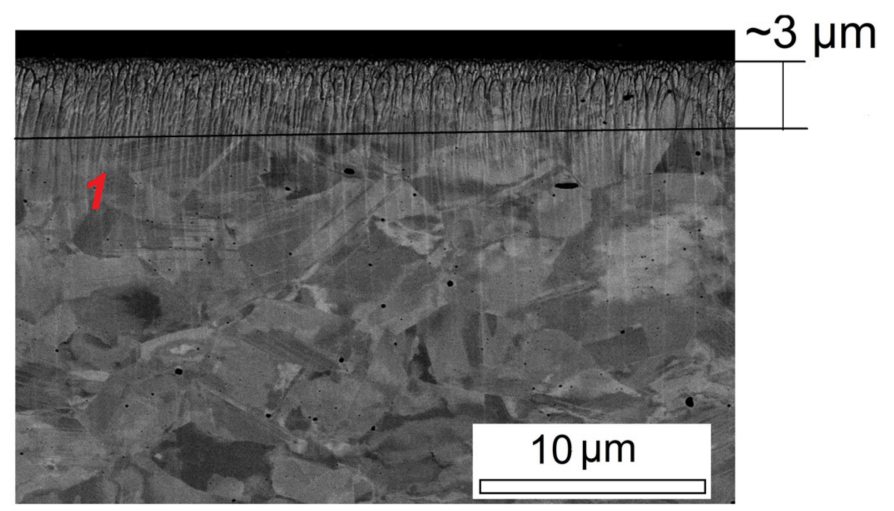

(b)

Figure 10. SEM image of a cut surface of a stainless steel sample in the initial (a) and after irradiation (b) states at various magnifications (1-the zone with relatively equiaxed grains, 2 - the zone of deformed grains).

\section{Conclusions}

- $\mathrm{Al}$ ion irradiation of AISI 321 stainless steel results in the changes in the composition and structural-phase state of the surface layers, which leads to an increase in the nanoand microhardness.

- The depth profile of implanted aluminum is a curve with a broad peak, the maximum concentration of aluminum of $27 \mathrm{at} \%$ is reached at a depth of $20 \mathrm{~nm}$ and is $27 \mathrm{at} \%$. A thin surface layer down to a depth of $30 \mathrm{~nm}$ after $\mathrm{Al}^{+}$ions implantation consists mainly of metal oxides.

- Irradiation results in the $\gamma \rightarrow \alpha^{\prime}$ phase transformation, and the increased amount of $\alpha^{\prime}$ in the irradiated samples was found at the depth of up to $1 \mu \mathrm{m}$. 
- Etching reveals a modified layer approximately $1 \mu \mathrm{m}$ thick, which is etched at a higher rate compared to the bulk sample. SEM analysis of the microstructure of the surface layers of AISI 321 steel approximately $100 \mu \mathrm{m}$ thick before and after irradiation revealed that the microstructure of this layer consists of two zones: Zone of equiaxed grains and deformed grains. After irradiation, the boundary between these zones becomes slightly more blurred and a decrease in the grain size is observed.

- The observed depth of phase and structure transformation in irradiated steel significantly exceeds the maximum depth of ion penetration.

- The novelty of the work consists of the ion irradiation investigation of as delivered (i.e., without additional stress relief annealing) AISI 321 stainless steel surface layers. This method can be applied for the elaboration surface modifying technique to provide the control of the functional properties of steel surface.

Author Contributions: Supervision, P.V.B.; writing—original draft preparation, V.Y.B.; writingreview and editing, V.V.T.; investigations, V.L.V., E.A.P., T.A.S., A.A.S., A.I.C. and S.S.A. All authors have read and agreed to the published version of the manuscript.

Funding: The work was carried out within the State Task of the Ministry of Science and Higher Education of Russian Federation (No. 121030100002-0).

Data Availability Statement: Data presented in this article are available at request from the corresponding author.

Acknowledgments: The work was performed with the equipment of the Center for Shared Usage "Center of Physical and Physical-Chemical Methods of Analysis and Research of Properties and Characteristics of Surfaces, Nanostructures, Materials, and Samples" of the UdmFRC UB RAS.

Conflicts of Interest: The authors declare no conflict of interest.

\section{References}

1. Heintze, C.; Recknagel, C.; Bergner, F.; Hernández-Mayoral, M.; Kolitsch, A. Ion-irradiation-induced damage of steels characterized by means of nanoindentation. Nucl. Instrum. Methods Phys. Res. Sect. B 2009, 267, 1505-1508. [CrossRef]

2. Figueroa, R.; Abreu, C.V.; Cristybal, M.J.; Pena, G. Effect of nitrogen and molybdenum ion implantation in the tribological behavior of AA7075 aluminum alloy. Wear 2012, 276, 53-60. [CrossRef]

3. Jin, J.; Chen, Y.; Gao, K.; Huang, X. The effect of ion implantation on tribology and hot rolling contactfatigue of Cr4Mo4Ni4V bearing steel. Appl. Surf. Sci. 2014, 305, 93-100. [CrossRef]

4. Hug, E.; Thibault, S.; Chateigner, D.; Maunoury, L. Nitriding aluminum alloys by N-multicharged ions implantation: Correlation between surface strengthening and microstructure modifications. Surf. Coat. Technol. 2012, 206, 5028-5035. [CrossRef]

5. Zhang, J.; Peng, S.; Zhang, A.; Wen, J.; Zhang, T.; Xu, Y.; Yan, S.; Ren, H. Nitrogen ion implantation on the mechanical properties of AISI 420 martensitic stainless steel. Surf. Coat. Technol. 2016, 305, 132-138. [CrossRef]

6. Straede, C.A.; Mikkelsen, N.J. Implementation of ion implantation in European industry. Surf. Coat. Technol. 1996, 84, 567-573. [CrossRef]

7. Li, W.; Chen, H.T.; Li, C.; Huang, W.Y.; Chen, J.; Zuo, L.; Ren, Y.J.; He, J.J.; Zhang, S.D. Microstructure and tensile properties of AISI 321 stainless steel with aluminizing and annealing treatment. Mater. Des. 2021, 205, 109729. [CrossRef]

8. Kasana, S.S.; Pandey, O.P. Effect of heat treatment on microstructure and mechanical properties of boron containing Ti-Stabilized AISI-321 steel for nuclear power plant application. Mater. Today Commun. 2021, 26, 101959. [CrossRef]

9. Kalchenko, A.S.; Bryk, V.V.; Lazarev, N.P.; Neklyudov, I.M.; Neklyudov, I.M.; Voyevodin, V.N.; Garner, F.A. Prediction of swelling of 18Cr10NiTi austenitic steel over a wide range of displacement rates. J. Nucl. Mater. 2010, 399, 114-121. [CrossRef]

10. Horvath, A.; Nagy, N.; Vertesy, G.; Schiller, R. The effect of ion irradiation on the electron work function of stainless steel. Mater. Chem. Phys. 2018, 217, 541-546. [CrossRef]

11. Lopatin, I.V.; Akhmadeev, Y.H.; Korneva, O.S.; Krysina, O.V.; Petrikova, E.A.; Prokopenko, N.A.; Ryabchikov, A.I.; Sivin, D.O. Low-energy plasma-immersion implantation of nitrogen ions in titanium by a beam with ballistic focusing. J. Phys. Conf. Ser. 2018, 1115, 032041. [CrossRef]

12. Piekoszewski, J.; Walis, L.; Langner, J. Surface morphology of nitrogen-alloyed steels using high intensity pulsed plasma beams. Mater. Lett. 1997, 32, 49-53. [CrossRef]

13. Blawert, C.; Weisheit, A.; Mordike, B.L.; Knoop, F.M. Plasma immersion ion implantation of stainless steel: Austenitic stainless steel in comparison to austenitic-ferritic stainless steel. Surf. Coat. Technol. 1996, 85, 15-27. [CrossRef]

14. Langguth, K.; Kluge, A.; Ryssel, H. Wear of steels after implantation of oxygen ions or oxidation at 670 K. Wear 1992, $155,343-351$. [CrossRef] 
15. Noli, F.; Misaelides, P.; Giorginis, G.; Baumann, H.; Hatzidimitriou, A. The effect of Zr-implantation on the thermal-oxidation and aqueous corrosion of AISI-321 stainless-steel. Nucl. Instrum. Methods Phys. Res. Sect. B 1995, 95, 197-207. [CrossRef]

16. Noli, F.; Lagoyannis, A.; Misaelides, P. Oxidation resistance of Y-implanted steel using accelerator based techniques. Nucl. Instrum. Methods Phys. Res. Sect. B 2008, 266, 2437-2440. [CrossRef]

17. Noli, F.; Misaelides, P.; Pavlidou, E. The beneficial role of Y-implantation on the aqueous corrosion of stainless steel. Surf. Coat. Technol. 2011, 205, 3506-3511. [CrossRef]

18. Noli, F.; Misaelides, P.; Giorginis, G.; Baumann, H.; Hausner, R. Application of nuclear analytical and electron microscopic techniques to the investigation of the oxidation behavior of Mg-implanted steel samples. Nucl. Instrum. Methods Phys. Res. Sect. B 1996, 113, 171-175. [CrossRef]

19. Noli, F.; Misaelides, P.; Giorginis, G.; Baumann, H. Investigation of the oxidation behavior of Mg-implanted steel samples. Oxid. Metals. 1997, 48, 225-241. [CrossRef]

20. Noli, F.; Misaelides, P.; Baumann, H.; Hatzidimitriou, A. The preparation, characterization and corrosion behaviour of ionimplanted and ceramic-coated AISI 321 steel samples. Corros. Sci. 1996, 38, 2235-2246. [CrossRef]

21. Noli, F.; Misaelides, P.; Spathis, P.; Pilakouta, M.; Baumann, H. Oxidation and corrosion studies of Al-implanted stainless-steel AISI-321 using nuclear-reaction and electrochemical techniques. Nucl. Instrum. Methods Phys. Res. Sect. B 1992, 68, 398-401. [CrossRef]

22. Noli, F.; Misaelides, P.; Giorginis, G.; Baumann, H.; Pavlidou, E. The effect of Al implantation on the thermal oxidation of stainless steel in aggressive environments. Oxid. Met. 2000, 53, 303-322. [CrossRef]

23. Noli, F.; Misaelides, P.; Pavlidou, E.; Theodossiu, W.; Riviere, J.P. Influence of implantation dose on the high-temperature oxidation of Al-implanted AISI-321 steel. Oxid. Met. 2001, 56, 571-582. [CrossRef]

24. Noli, F.; Misaelides, P.; Bethge, K. Aluminum diffusion in Al-implanted AISI 321 stainless steel using accelerator-based characterization techniques. Nucl. Instrum. Methods Phys. Res. Sect. B 1998, 139, 322-326. [CrossRef]

25. Hausner, R.M.; Baumann, H.; Bethge, K. Aluminum ion implantation under backfilling oxygen. Nucl. Instrum. Methods Phys. Res. Sect. B 1996, 113, 176-181. [CrossRef]

26. Tiamiyu, A.A.; Zhao, S.T.; Li, Z.Z.; Odeshi, A.G.; Szpunar, J.A. Thermal and mechanical stability of austenite in metastable austenitic stainless steel. Metall. Mater. Trans. A 2019, 50, 4513-4530. [CrossRef]

27. Emurlaev, K.I.; Bataev, I.A.; Lazurenko, D.V.; Burov, V.G.; Ivanov, I.V.; Emurlaeva, Y.Y. Deformation-induced martensite transformation in AISI 321 stainless steel under dry sliding friction. Mater. Today Proc. 2020, 25, 424-427. [CrossRef]

28. Neslusan, M.; Sugarova, J.; Hausild, P.; Minarik, P.; Capek, J.; Jambor, M.; Sugar, P. Barkhausen noise emission in AISI 321 austenitic steel originating from the strain-induced martensite transformation. Metals 2021, 11, 429. [CrossRef]

29. Su, Y.; Xia, S.Q.; Huang, J.; Liu, Q.Y.; Liu, H.C.; Wang, C.X.; Wang, Y.G. Irradiation behaviors in BCC multi-component alloys with different lattice distortions. Metals 2021, 11, 706. [CrossRef]

30. Oliver, W.; Pharr, G. An improved technique for detemining hardness and elastic modulus using load and displacement sensing indentation experiments. J. Mater. Res. 1992, 7, 1564-1583. [CrossRef]

31. Shelekhov, E.V.; Sviridova, T.A. Program for X-ray analysis of polycrystals. Metal Sci. Heat Treat. 2000, 42, 309-313. [CrossRef]

32. SRIM-2013. Available online: http:/ / www.srim.org (accessed on 25 August 2021).

33. NIST XPS Database. Available online: https://srdata.nist.gov/xps/EnergyTypeValSrch.aspx (accessed on 7 January 2021).

34. Liu, F.C.; Dong, P.; Lu, W.; Sun, K. On formation of Al-O-C bonds at aluminum/polyamide joint interface. Appl. Surf. Sci. 2019, 466, 202-209. [CrossRef]

35. Ardelean, H.; Petit, S.; Laurens, P.; Marcus, P.; Arefi-Khonsari, F. Effects of different laser and plasma treatments on the interface and adherence between evaporated aluminium and polyethylene terephthalate films: X-ray photoemission, and adhesion studies. Appl. Surf. Sci. 2005, 243, 304-318. [CrossRef]

36. Preda, I.; Mossanek, R.J.O.; Abbate, M.; Alvarez, L.; Méndez, J.; Gutiérrez, A.; Soriano, L. Surface contributions to the XPS spectra of nanostructured NiO deposited on HOPG. Surf. Sci. 2012, 606, 1426-1430. [CrossRef]

37. Rodríguez, J.L.; Valenzuela, M.A.; Poznyak, T.; Lartundo, L.; Chairez, I. Reactivity of NiO for 2,4-D degradation with ozone: XPS studies. J. Hazard. Mater. 2013, 262, 472-481. [CrossRef]

38. Nesbitt, H.W.; Legrand, D.; Bancroft, G.M. Interpretation of Ni2p XPS spectra of Ni conductors and Ni insulators. Phys. Chem. Miner. 2000, 27, 357-366. [CrossRef]

39. Andreev, Y.Y.; Safonov, I.A. The negative adsorption of chromium atoms on alloy-oxide film boundaries during Ox-idation in air and anodic passivation of Fe-Cr and Ni-Cr alloys. Russ. J. Phys. Chem. A 2009, 83, 1768-1774. [CrossRef]

40. Sakamoto, I.; Hayashi, N.; Tanoue, H. Behavior of rare-gas atoms implanted in stainless-steel. Surf. Coat. Technol. 1994, 65, 133-136. [CrossRef]

41. Xu, C.L.; Liu, X.B.; Xue, F.; Li, Y.F.; Qian, W.J.; Jia, W.Q. Irradiation-induced BCC-phase formation and magnetism in a 316 austenitic stainless steel. Nucl. Eng. Technol. 2020, 52, 610-613. [CrossRef]

42. Lin, J.W.; Chen, F.D.; Tang, X.B.; Liu, J.; Shen, S.K.; Ge, G.J. Radiation-induced swelling and hardening of 316L stainless steel fabricated by selected laser melting. Vacuum 2020, 174, 109183. [CrossRef]

43. Budzynski, P. Long-range effect in nitrogen ion-implanted AISI 316L stainless steel. Nucl. Instrum. Methods Phys. Res. Sect. B 2015, 342, 1-6. [CrossRef] 
44. Ovchinnikov, V.V. Radiation-dynamics effects. Potential for producing condensed media with unique properties and structural states. Phys. Usp. 2008, 51, 955-964. [CrossRef]

45. Bayankin, V.Y.; Novoselov, A.A.; Gilmutdinov, F.Z. On segregation manifestations of the long-range effect during the ion implantation of rolled copper-nickel foils. J. Surf. Investig. X-ray Synchrotron Neutron Tech. 2014, 8, 182-186. [CrossRef] 